\title{
Notas sobre o conceito de sociabilidade legal em Kant
}

\author{
Notes on the concept of legal sociability in Kant
}

\section{Rejane Schaefer Kalsing ${ }^{[a]}$, Delamar José Volpato Dutra ${ }^{[b]}$}

[a] Doutorado em Filosofia pela Universidade Federal de Santa Catarina (UFSC), professora efetiva do ensino básico, técnico e tecnológico - área de Filosofia no Instituto Federal de Educação, Ciência e Tecnologia Catarinense, Sombrio, SC - Brasil, e-mail: rejane.kalsing@yahoo.com.br

[b] Doutorado em Filosofia pela Universidade Federal do Rio Grande do Sul (UFRGS), professor associado da Universidade Federal de Santa Catarina (UFSC), Florianópolis, SC - Brasil, e-mail: djvdutra@yahoo.com.br

\section{Resumo}

Para Kant, humanidade significa o universal sentimento de participação e a faculdade de comunicação íntima e universal, sendo o que distingue o homem do animal. Dessa formulação, surge o conceito de sociabilidade legal, pelo qual um povo constitui uma coletividade duradoura, capaz de conciliar liberdade, igualdade e coação. Rohden sustentou que esse conceito, apesar de se relacionar com o contexto estético, não se restringiria a este, implicando uma compreensão ampliada do conceito de humanidade. A partir de tal hipótese, poder-se-ia entender também a sociabilidade legal como um pré-requisito para uma constituição política, no sentido de uma capacidade e disposição para se deixar guiar por princípios do direito. Nesse sentido, o direito constituir-se-ia na forma da sociabilidade legal e na possibilidade de expressá-la concretamente. O objetivo deste 
texto é examinar em que sentido essa interpretação do conceito de sociabilidade legal sugerida por Rohden pode ou não corresponder ao texto kantiano.

Palavras-chave: Kant. Sociabilidade legal. Direito. Sociedade. Humanidade.

\begin{abstract}
According to Kant, humanity means the universal sense of participation and the ability of intimate and universal communication. These properties form the sociability that is related to humanity, as distinct from animal. It appears, at this point, that the concept of legal socialization is necessary for the establishment of a lasting community, capable of uniting freedom, equality and coercion. Rohden sustained that this concept, although related to aesthetics, overflows the Critique of Judgement. From this hypothesis, it is possible to see sociability as a legal pre-requisite for a political constitution, in the sense of one's capacity and inclination to be guided by principles of law. Thus, law would be constituted both in the form of legal sociability and its concrete expression. The purpose of this paper is to examine in what sense these various biases of interpretation of legal sociability sustained by Rohden may or may not correspond to the Kantian text.
\end{abstract}

Keywords: Kant. Legal sociability. Law. Society. Humanity.

\title{
Introdução
}

Este texto dissertará sobre a interpretação dada por Valério Rohden ao conceito kantiano de sociabilidade legal, que ocorre no $\$ 60$ da Crítica da Faculdade do Juízo, interpretação que é apresentada em seu artigo "Sociabilidade legal uma ligação entre direito e humanidade na terceira crítica de Kant".

O presente escrito trata-se, na verdade, de um excerto, modificado, por assim dizer, da tese defendida pela autora deste, ou seja, Rejane Schaefer Kalsing, em 31 de janeiro deste ano, intitulada "Sociabilidade legal: uma ligação entre sociabilidade e direito em Kant”, a qual foi orientada por Delamar José Volpato Dutra, que escreve em conjunto o presente artigo, e co-orientada por Valério Rohden. Infelizmente, o próprio Rohden não pôde participar, em função do seu falecimento, 
ocorrido em setembro de 2010, nem da qualificação nem da defesa dessa tese, já que a primeira ocorreu em 22 de outubro de 2010.

O opúsculo de Rohden é muito rico, sugere uma compreensão ampla do conceito de sociabilidade legal de Kant, podendo, por isso, prestar-se como uma chave de interpretação do referido conceito. Rohden extrapola, inclusive, a própria Crítica da Faculdade do Juízo, que é a única obra na qual ocorre o conceito de sociabilidade legal, estendendo a compreensão do mesmo para outras obras de Kant, como Ideia de uma história universal de um ponto de vista cosmopolita e Início conjectural da história humana. É pela sociabilidade legal que um povo constitui uma coletividade duradoura, conforme Kant e, nesse sentido, entende Rohden que a sociabilidade legal seria um pré-requisito para uma constituição política e, por conseguinte, poderia significar a capacidade e disposição a se deixar guiar por princípios do direito.

Sabe-se que na obra Ideia, a constituição civil perfeita é a mais alta tarefa da natureza para a espécie humana e que no Início conjectural essa mesma constituição é o objetivo mais alto da cultura. Dessa forma, entendendo-se a sociabilidade legal como um pré-requisito para uma constituição política, Rohden teria razão em ver este conceito implicado tanto na obra Ideia de uma história universal de um ponto de vista cosmopolita e no Início conjectural da história humana.

Além disso, o autor depreende do texto de Kant que o sentido do conceito de sociabilidade legal é a capacidade e disposição a se deixar guiar por princípios do direito. Segundo Rohden, é pela capacidade de se impor uma obrigação racional que o ser humano é capaz de sociedade em Kant, e não o contrário. É porque pode se obrigar, se responsabilizar, agir segundo regras de convivência, que o ser humano tem condições de vida coletiva. Sem a capacidade e disposição de se deixar guiar por princípios do direito a sociedade é impossível, conclui Rohden.

Essa compreensão ampla, por assim dizer, do conceito sociabilidade legal, quer dizer, pensá-lo como um pré-requisito para uma constituição política e, por conseguinte, como a capacidade e disposição a se deixar guiar por princípios do direito, - entendendo que, sem essa capacidade e disposição, a sociedade é impossível e, além disso, ampliando a compreensão desse conceito para outras obras de Kant, como, por exemplo, 
Ideia de uma história universal de um ponto de vista cosmopolita e Início conjectural da história humana, - foi o que inspirou o projeto da referida tese. Ou seja, pensar a sociabilidade legal como um requisito necessário à sociedade, quer dizer, como uma condição sem a qual ela é impossível em Kant, foi o que propriamente inspirou o projeto da referida tese.

A tese procurou investigar em que sentido a sociabilidade pensada por Kant nas três obras referidas, ou seja, Crítica da Faculdade do Juízo, Ideia de uma história universal de um ponto de vista cosmopolita e Início conjectural da história humana, pode ser uma sociabilidade legal e, sendo assim, ela constituiria uma ligação entre sociabilidade e direito em Kant. Além dessas obras, a tese versou também sobre a obra kantiana Doutrina do direito. Entretanto, o presente texto baseia-se apenas no capítulo dedicado à obra Crítica da Faculdade do Juízo e, procura, então, apresentar de forma resumida os resultados do mesmo.

\section{0 conceito de sociabilidade legal}

O conceito de sociabilidade legal ocorre propriamente no $\S 60$, o Apêndice da Crítica da faculdade de juízo estética, primeira parte da Crítica da Faculdade do Juízo (Kritik der Urteilskraft - KU), o qual é denominado "Da doutrina do método do gosto". No artigo sobre o tema, intitulado "Sociabilidade legal uma ligação entre direito e humanidade na terceira crítica de Kant”, Rohden (1994, p. 97) afirma que “a expressão 'sociabilidade legal', mesmo mantendo relação com o contexto estético, transborda os limites da própria terceira Crítica, na direção de uma compreensão ampliada do conceito de humanidade". Essa é a tese que ele quer defender no referido artigo. Assim, apesar de o conceito de sociabilidade legal se relacionar com o contexto estético, até porque é nesse contexto que o mesmo ocorre, a seu ver, ele não se restringiria a tal contexto, transbordando inclusive a própria $K U$ no sentido de uma compreensão ampliada do conceito de humanidade.

No intuito de iniciar esta análise, começar-se-á por referir o $§ 44$, no qual Kant (2002, p. 150) declara que "não há uma ciência do belo, mas somente crítica, nem uma ciência bela, mas somente arte bela". Desse 
modo, só é possível fazer uma crítica do belo, no sentido de uma "investigação, "[de um] rigoroso exame" (KANT, 2002 p.14) da faculdade do gosto, enquanto faculdade de juízo estética" (KANT, 2002, p.14). A respeito da propedêutica de toda arte bela, afirma, no §60, que ela,

na medida em que está disposta para o mais alto grau de sua perfeição, não parece encontrar-se em preceitos mas na cultura das faculdades do ânimo através daqueles conhecimentos prévios que se chamam humaniora, presumivelmente porque humanidade $<$ Humanität $>$ significa de um lado o universal sentimento de participação [allgemeine Teilnehmungsgefühl] e, de outro, a faculdade de poder comunicar-se íntima e universalmente [das Vermögen sich innigst und allgemein mittheilen zu können]; estas propriedades coligadas constituem a sociabilidade conveniente à humanidade $<$ Menschheit $>$, pela qual ela se distingue da limitação animal (KANT, 2002, p. 199).

Deve-se entender "que", "para" a arte bela, enquanto dirigida para o mais alto grau de sua perfeição, uma introdução a ela, enquanto fase preliminar, não se encontra em regras ou mandamentos e sim no cultivo das faculdades do ânimo, chamada humaniora. Trata-se, dessa forma, "de uma propedêutica humanística, justificada mediante o fato de o conceito de humanidade estar implicado na fundação da validade do tipo de juízos em causa" (ROHDEN, 1994, p. 98). De fato, Kant compreende o cultivo das faculdades do ânimo, a partir do que se chama humaniora, como a propedêutica da arte bela, porque, presumivelmente, como diz, o conceito de humanidade tem dois significados: aquele de um universal sentimento de participação e aquele "de" uma faculdade de comunicação íntima e universal. São estas duas qualidades unidas que constituem a sociabilidade que convém à humanidade, através da qual a humanidade se distingue da limitação animal.

A partir dessas duas propriedades, quais sejam, o universal sentimento de participação e a faculdade de poder comunicação íntima e universal, que coligadas constituem a sociabilidade que convém à humanidade e pela qual ela se distingue da limitação animal, Rohden (1994, p. 99) compreende essa sociabilidade como uma "sociabilidade universal". Quer dizer, a sociabilidade presente nesse momento do texto kantiano é constituída de dois momentos, os quais são entendidos por 
Kant como universais. É por esse motivo que Rohden pode compreender tal sociabilidade como uma sociabilidade universal. Mais que isso, é essa sociabilidade que é a conveniente para a humanidade, sendo, por meio dela, que a humanidade se distingue da animalidade.

O momento em que Kant (2002, p. 200) apresenta propriamente o conceito sociabilidade legal é o seguinte:

a época e os povos, nos quais o ativo impulso à sociabilidade legal, pela qual um povo constitui uma coletividade duradoura, lutou com as grandes dificuldades que envolvem a difícil tarefa de unir liberdade (e, portanto, também igualdade) à coerção (mais do respeito e da submissão por dever do que por medo).

Há que se ressaltar, antes de mais nada, que o conceito de sociabilidade legal não mais ocorre na obra. Rohden destaca que, "no referido texto da 'Crítica da Faculdade do Juízo' (CFJ), Kant limita-se a observar, a respeito da sociabilidade legal, que é por ela que um povo constitui uma república duradoura" (ROHDEN, 1994, p. 99-100). Ou seja, o momento em que tal conceito se apresenta é somente esse e são essas as únicas observações que Kant faz a respeito dele.

Um outro problema, se assim se quiser formular, ou pelo menos um outro aspecto digno de nota, é a reduzida atenção da literatura especializada que tal conceito recebeu (ROHDEN, 1994, p. 97). Talvez, isso se deva justamente à reduzida atenção dada pelo próprio Kant e também pela abordagem um tanto deslocada desta, já que o conceito de sociabilidade legal deveria ter sido abordado de modo especial em sua filosofia do direito, coisa que não ocorreu.

Em relação ao texto de Kant, o primeiro aspecto a ressaltar é a sua afirmação de que é pela sociabilidade legal que um povo constitui uma coletividade duradoura. Sendo assim, ela parece se configurar como um requisito necessário para o caráter duradouro da coletividade. Um segundo ponto é que "o texto refere-se a um outro aspecto preliminar, da época e os povos em que o impulso à sociabilidade legal se efetuou, quer dizer, do momento propício à efetuação dessa sociabilidade" (ROHDEN, 1994, p. 97). Na época e nos povos em que se deu esse ativo impulso à sociabilidade legal, este impulso teve de lutar com as grandes dificuldades 
que envolvem o empreendimento de unificar a liberdade e a igualdade à coerção. Quer dizer, a sociabilidade legal surgiu a partir da união de liberdade, igualdade e coerção. Coerção esta que deveria ser mais no sentido do respeito e da submissão por dever do que da coerção por medo.

Essa união, como afirma o texto, foi uma tarefa difícil, pois possuía grandes dificuldades, com as quais o ativo impulso à sociabilidade legal teve de lutar para então efetivá-la. No feliz comentário de Rohden, "para que tal efetivação se desse, seria preciso coadunar liberdade, igualdade e coerção de uma forma ética, ou seja, teria que tratar-se de uma coerção mais do respeito e da submissão por dever do que por medo" (ROHDEN, 1994, p. 97).

Pode-se perguntar, ainda, com Rohden, "como se concebe a sociabilidade legal nas perspectivas do Direito e da Ética?" (ROHDEN, 1994, p. 101). Segundo Rohden, a "afirmação do texto é de que por ela um povo constitui uma república duradoura. Ela tem de ser entendida, pois, como pré-requisito para uma constituição política" (ROHDEN, 1994, p. 101). Em outras palavras, como é a partir de uma sociabilidade legal que um povo constitui uma coletividade ou uma república duradoura, ela deve ser considerada como requisito prévio e indispensável para a instauração de uma constituição política.

Em seguida à passagem antes referida, Kant (2002, p. 200) destaca que

uma tal época e um tal povo teriam de inventar primeiro a arte da comunicação recíproca das ideias da parte mais culta com a mais inculta, o acordo [Abstimmung] da ampliação e do refinamento da primeira com a natural simplicidade e originalidade da última e, deste modo inventar primeiro aquele meio termo entre a cultura superior e a simples natureza, o qual constitui também para o gosto, enquanto sentido humano universal, o padrão de medida correto que não pode ser indicado por nenhuma regra universal.

Para que a sociabilidade se efetivasse, como já visto, foi preciso coadunar liberdade, igualdade e coerção de uma forma ética, no sentido de uma coerção mais ligada ao respeito e à submissão por dever do que ao medo. Pode-se perguntar: como, de que forma isso pôde ter acontecido? Quiçá, um modo pelo qual se deu essa união entre 
liberdade, igualdade e coerção, união que teria engendrado a sociabilidade legal, tenha sido, primeiramente, por meio da invenção de uma comunicação recíproca de ideias entre a parte mais culta com a parte mais inculta desse povo. A partir dessa comunicação recíproca de ideias se poderia chegar a um acordo entre a ampliação e o refinamento da parte mais culta com a simplicidade e originalidade da parte mais inculta do povo. Desse modo, poder-se-ia inventar um meio termo entre a cultura superior e a simples natureza. Meio termo que constitui, para Kant, o padrão de medida correto que não pode ser indicado por nenhuma regra universal que, sem embargo disso, serve de padrão, inclusive para o gosto, o qual é aqui entendido enquanto sentido humano universal.

Somente depois de se ter criado, a partir do acordo entre as diferentes partes do povo, um meio termo que seria o padrão de medida correto, inclusive para o gosto, como já frisado, é que pode ter ocorrido o impulso à sociabilidade legal. Pois, a partir disso, conforme Kant, poder-se-ia obter "a unificação feliz em um e mesmo povo da coerção legal da mais elevada cultura com a força e a correção da natureza livre que sente seu próprio valor (Idem). Portanto, para se chegar propriamente à sociabilidade legal, pela qual um povo constitui uma coletividade duradoura, é preciso coadunar liberdade, igualdade e coerção. E, para se chegar a isso, é necessário criar, antes, uma comunicação recíproca de ideias entre as diferentes partes desse povo, mais precisamente, entre a mais culta e a mais inculta para se chegar a um meio termo entre as duas, o qual constitui o padrão de medida correto.

A esse respeito, Rohden (1994, p. 101) declara que Kant

sugere vários níveis da questão: o da constituição de uma coletividade duradoura, que por sua vez se funda numa sociabilidade legal, a qual remete, enfim, a uma preparação moral. A isso Kant acrescenta que essa preparação implicaria a necessidade de inventar primeiro a arte da comunicação entre a parte mais culta e a inculta.

Haveria, assim, diversos níveis da questão, sendo um deles o de como se conceber a sociabilidade legal nas perspectivas do direito e da ética, antes referidas. Da afirmação de Rohden é possível se depreender que o quarto e último nível é aquele da constituição de uma coletividade duradoura. O terceiro, no qual aquele se funda, é o da sociabilidade legal que, por sua vez, 
se reporta a uma preparação moral, o qual é, então, o segundo nível. O primeiro nível seria necessário ao segundo, a saber, a invenção de uma arte da comunicação recíproca entre a parte mais culta e a mais inculta de um povo. Rohden, apoiando-se em Werner Busch, mais precisamente na obra Die Entstehung der kritischen Rechtsphilosophie Kants 1762-1780, afirma que o aspecto mais interessante da concepção kantiana de sociabilidade

é a inversão da tese de Aristóteles e de vários antecessores de Kant, que viam o fundamento do Direito na inclinação do homem à sociedade, enquanto Kant viu o conceito de Direito como condição de possibilidade da sociedade. Ou seja, o homem não é originariamente social, mas sociável: é graças à sua capacidade de impor-se uma obrigação racional que o homem é capaz de sociedade (ROHDEN, 1994, p. 104).

De acordo com isso, ao contrário de alguns de seus antecessores e também de Aristóteles, para Kant não é a inclinação do ser humano à sociedade que funda o Direito e sim o contrário, é o Direito que funda a possibilidade da sociedade. Em outras palavras, é em função da capacidade do ser humano se impor uma obrigação racional que é possível a sociedade. O ser humano, para Kant, não é originariamente social, mas sociável, de tal forma que não poderia ser a sua inclinação à sociedade a fundar o direito e sim o contrário. Isso implica entender o direito, entre outras coisas, como a capacidade de se impor uma obrigação racional, pela qual, então, o ser humano se torna capaz de sociedade.

Tal afirmação de Rohden refere-se não propriamente à obra em questão, a KU, e sim à Observações sobre o sentimento do belo e do sublime, justamente aquela que Busch analisa. Apesar de Busch não se referir à $K U$ ou à Doutrina do direito, Rohden faz a aproximação da reflexão sobre o conceito de sociabilidade legal.

Rohden assevera que

pela capacidade de obrigar-se, responsabilizar-se, ser cidadão, o homem tem condições de vida coletiva. A capacidade de vida em sociedade fundada no Direito é a capacidade de agir segundo regras e princípios de convivência. Sem essa capacidade e disposição de deixar-se guiar por eles, a sociedade é impossível. Com isso fica claro o sentido da sociabilidade legal: ela é a capacidade e disposição a deixar-se guiar por princípios do Direito (ROHDEN, 1994, p. 104). 
Justamente porque o ser humano é capaz de se impor uma obrigação e de se responsabilizar por suas ações é que ele tem condições de vida coletiva, é capaz de viver em sociedade. Isso significa ser capaz de agir conforme regras e princípios de convivência. Se o ser humano não tivesse essa capacidade, não seria possível a sociedade.

A partir desse raciocínio, Rohden conclui que o sentido da sociabilidade legal seria o da capacidade e disposição a deixar-se guiar por princípios do Direito. Há que se destacar aqui duas coisas: primeiro, a sociabilidade legal é a capacidade de se guiar por princípios do Direito; segundo, ela é a disposição de se deixar guiar por princípios do Direito. Desse modo, o ser humano é capaz de se guiar, de orientar suas ações. Além disso, Rohden afirma que "o Direito é a forma da liberdade exercer-se racionalmente, ou seja, é a forma da sociabilidade legal e é também a possibilidade de expressá-la concretamente" (ROHDEN, 1994, p. 105). De acordo com isso, portanto, a forma da sociabilidade legal é o direito, e ele é também a possibilidade daquela se expressar de forma concreta. Vale lembrar, no presente contexto, que a forma de manifestação da sociabilidade não é a moral ou o sensus communis do gosto estético, mas o direito.

Contudo, o que o texto kantiano diz exatamente é que a sociabilidade legal se constitui numa espécie de pré-requisito para o direito. Ela não é propriamente o direito e sim uma preparação para ele. Ela se refere a um momento anterior, que antecede o direito, um estado pré-jurídico, como diria Pinzani (2005, p. 75). Assim sendo, o direito não poderia ser a forma da sociabilidade legal e nem a possibilidade de expressão concreta dessa. Relembrando a passagem, ela diz que a época em que se deu o ativo impulso à sociabilidade legal, por meio da qual um povo constitui uma coletividade duradoura, esse impulso teve de lutar com as grandes dificuldades que envolvem a tarefa de unir liberdade, igualdade e coerção (KANT, 2002, p. 200). Ou seja, a sociabilidade legal se constitui em uma condição preliminar para o direito, não o direito propriamente, que é o que Rohden está a dizer.

O próprio Rohden (1994, p. 100), em passagens anteriores, afirma, diferentemente, que a sociabilidade legal "tem de ser entendida, pois, como pré-requisito para uma constituição política”, pois é a partir dela que se constituirá uma coletividade duradoura ou república 
duradoura. A sociabilidade legal é, portanto, uma condição preliminar para que essa coletividade ou para que uma constituição política se efetue. Sendo assim, ela deve (pode) ser entendida como uma espécie de pré-requisito, condição preliminar também para o direito, mas não como o direito propriamente dito.

O próprio intérprete não deixa de observar que "o texto [a passagem da sociabilidade legal] refere-se a um [...] aspecto preliminar, da época e dos povos onde o impulso à sociabilidade legal se efetuou, quer dizer, o momento propício à efetuação dessa sociabilidade" (ROHDEN, 1994, p. 100).

Aqui, Rohden sugere que seria um aspecto preliminar, o da época em que o impulso à sociabilidade legal se deu época essa que teria sido o momento propício à efetuação da sociabilidade legal. Ou seja, a época em que esse impulso se deu foi também o momento propício para que a sociabilidade legal se efetuasse. Em outras palavras, quando a sociabilidade legal se efetuou, ela já tinha preliminares operando. A sociabilidade seria uma preliminar à constituição de uma coletividade duradoura, de tal forma que, sendo assim, a sociabilidade legal só poderia ser anterior ao próprio direito e, por conseguinte, o direito não poderia ser a forma da sociabilidade legal e nem a possibilidade de expressá-la concretamente, como assevera Rohden. Portanto, o direito é um momento posterior ao da sociabilidade legal, consistindo esta, por sua vez, em uma espécie de pré-requisito, de condição preliminar para a efetivação daquele, como que uma preparação para ele.

\section{Considerações finais}

O conceito sociabilidade legal ocorre apenas uma única vez, como referido, na obra $K U$. Como visto, Kant entende que é por ela que um povo constitui uma coletividade duradoura, cujo ativo impulso teve de lutar com as grandes dificuldades que envolvem a tarefa de unir liberdade e coerção. Nesse sentido, a sociabilidade legal deve ser entendida como um pré-requisito para uma constituição política e, além disso, como a capacidade e disposição a se deixar guiar por princípios do Direito. 
Enquanto condição preliminar para que a coletividade duradoura se efetue, a sociabilidade legal pode ser entendida como uma espécie de pré-requisito, como um momento anterior ao direito, de tal forma que prepara ou conduz ao direito. Sendo um requisito, uma condição preliminar para o direito, ela é, portanto, necessária para o seu surgimento. Numa palavra, ela é uma condição necessária para o direito já que, sem essa capacidade e disposição a se deixar guiar por seus princípios, não só a sociedade é impossível, conforme Rohden, mas também o próprio direito.

\section{Referências}

KANT, I. Gesammelte Schriften. Berlin; Leipzig: Königlich Preussischen Akademie der Wissenschaften, 1910.

KANT, I. Crítica da faculdade do juízo. Tradução de Valério Rohden e António Marques: Kritik der Urteilskraft. Rio de Janeiro: Forense Universitária, 2002.

KANT, I. Ideia de uma história universal de um ponto de vista cosmopolita. Tradução de Rodrigo Naves e Ricardo Terra. São Paulo: Brasiliense, 1986. (Coleção Elogio da Filosofia).

PINZANI, A. Der systematische stellenwert der pseudo-ulpianischen Regeln in Kants Rechtslehre. Zeitschrift für philosophische Forschung, v. 59, n. 1, p. 71-94, 2005.

ROHDEN, V. Sociabilidade legal uma ligação entre direito e humanidade na $3^{\text {a }}$ Crítica de Kant. Analytica, Rio de Janeiro, v. 1, n. 2, p. 97-106, 1994.

Recebido: 29/07/2011

Received: 07/29/2011

Aprovado: 30/11/2011

Approved: 11/30/2011 